\section{ORGANIZATION OF RESEARCH IN THE U.S.S.R. INSTITUTE OF PHYSICAL PROBLEMS}

O May 18, 1943, Prof. P. Kapitza presented a very long report at the meeting of the presidium of the U.S.S.R. Academy of Sciences in which he dealt with the organization of scientific work at the Academy of Sciences. An official translation into English of parts of the report has recently been made available in Great Britain in Bulletin, 9-10, 1943, of VOKS, the organ of the U.S.S.R. Society for Cultural Relations with Foreign Countries, and has been used in the preparation of the following account*.

On the basis of his experience at Cambridge, Prof. Kapitza felt that the organizational forms of scientific work accepted in the West could not be applied unchanged in the U.S.S.R. "This is principally caused by the fact that in our socialist country science occupies a special place. Of course it is well known and commonly accepted in the other countries too, that science plays a great role in the development of the culture and technology of the country. But in our country science is recognized as one of the essential mainstays of the development of culture and is accorded a leading position in the development of our technology and national economy. For this reason the organization of science in our country must have a more purposeful character than that to be found in other countries, where it is rather accidental and spontaneous. The connection between science and life must be close and more complete."

As Prof. Kapitza's Institute is so young -it is only seven or eight years old-and moreover is devoted to work, on strong magnetic fields and low temperatures, which was but little developed in the U.S.S.R. at the time, the first years were spent in forming and training the scientific personnel and staff. "The question I put before myself from the very outset was what sort of problems must an institute of the Academy of Sciences work up ? . . . I had in mind an institute of physics or . . . an institute devoted to research in the field of natural science. . . . I emphasize further that I am speaking in particular of the organization of an institute of the Academy of Sciences. What is the Academy of Sciences? It is the Chief Headquarters of Soviet Science. In my opinion it is called upon to direct all our science ideologically, from top to bottom, along a sound channel. Each of its separate institutes must pursue the same policy, that is, aspire to wield a directing influence on science in the field in which it is working, and strive to bring it into the front ranks. For this reason, the first task which an institute of the Academy of Sciences must set itself is to study a great science." In the official translation, 'great' is used throughout, but from the definition given it would appear that the correct translation is 'pure' as distinct from applied science. 'Great' science is "the science that studies the essential phenomena necessary for the most profound knowledge of nature", but it is explained that "the task of a science is to give the necessary knowledge for transforming nature so that it can serve man in his cultural development". For this reason the choice of the fields of research of an institution is extra-

- A complete translation of the speech together with that of a long discusilon has been made by the Sclence Section of the Society for Cultural Relations with the U.S.S.R., 98 Gower Street, London, W.C.1. ordinarily important, and Prof. Kapitza would choose the fields of low temperatures, the atomic nucleus and the solid state as the most important at the present time.

"Only a person with a profound creative talent and one who treats his work creatively can achieve considerable success in 'great science'. For this reason the leading group of the institute must un. doubtedly be formed from a few carefully picked workers who must devote themselves wholeheartedly to scientific work with not more than twenty per cent of their time given up to social or other non-scientific activities." From the emphasis laid upon conditions that the worker must be able to stay in the laboratory and himself work there, it is clear that Prof. Kapitza would not approve of what might be called 'office' research in which meetings and memoranda continually interrupt actual research work. "Only when one works in the laboratory oneself, with one's own hands, conducting experiments even the most routine parts of them,- - only under these conditions can real results be achieved in science. Good work cannot be done with other people's hands. . . I I am certain, that the very moment even the greatest scientist stops working in the laboratory himself, he not only ceases to develop but, in general, ceases to be a scientist. These principles are very important, but they belong only to peace-time; war-time forces us to act differently."

The greatest emphasis is laid upon these principles, particularly with beginners. "For this purpose I try to put their work into rather rigid organizational frames. For instance, a scientific worker must not be occupied with several subjects at one time, especially if he is at the beginning of his scientific career. When the scientific worker has grown somewhat and become more experienced, he may be able to work simultaneously on two or three subjects as a rare exception; but he must always begin with one."

Attention is then directed to the dangers of overwork. "The next point in the organization to ensure successful work, is that the scientist must work in the laboratory a limited number of hours. Long spells of work are harmful; it is exhausting and lowers a person's creative powers." The regime observed by the workers in the Institute for Physical Problems at Moscow is that usually all laboratory work stops at 6 p.m., after which the worker leaves for home "to ponder on his work, read, study and rest". Exceptionally, by permission of the vicedirector, work may continue until 8 p.m. Night work is sanctioned only by the director when it is justified by technical necessities of the experiment.

The next problems discussed are how such an Institute can influence the development of the science of the country and can avoid becoming a closed and isolated unit, which latter would be contrary to one of the principles laid down earlier. Several means are discussed. First of all, full advantage must be taken of the privileges of an institute of the Academy of Sciences, whereby the Institute has access to "rich and modern technical equipment" and to a wide field in selecting experienced staff. The special plant for making liquid helium in quantity gives the Institute for Physical Problems exceptional possibilities for doing experiments at very low temperatures. Next, these facilities are made available to workers in other institutes. Such visits are usually arranged as follows. "The comrade who wishes to work at our institute is invited to our scientific meeting where he reports on 
the experiment he proposes to conduct. This is discussed and, if the proposal is of scientifically grounded interest and the author is sufficiently qualified, he is given the opportunity to do his work." Not more than two or three outside workers can be accommodated at the same time without disorganizing the main work of the Institute. So far there have been more suitable applications than could be accommodated.

These guests form a vital link with other institutes, for not only is a knowledge of the work of the Institute for Physical Problems spread by them but also the guests keep the Institute informed of what is being done elsewhere. Prof. Kapitza is no believer in isolation, as the following passage shows. "In the future similar vital contacts must be established with scientists in other countries. Scientific workers from abroad visited us during the first years of the existence of our Institute. But in recent years the political situation has grown so complicated, that though there were those who wanted to come here, our connections with foreign countries had been severed, so we can only speak of this aspect of our relations with foreign scientists in view of plans for the future. But these relations must, of course, be deemed a normal and sound condition of the work of any academic institute, because science throughout the world comprises one indivisible whole."

Another function of the Institute is to train scientific workers. Prof. Kapitza was not satisfied with the external method of selecting postgraduate students. "Only the institute itself can train its future personnel, and it must do so with great diligence, by gradually nurturing them from youth." The method of selection used for two or three years before the War gave unique opportunities to students at the University of Moscow. "Taking advantage of the fact that we possess greater amounts of liquid helium for experiments at low temperatures than the refrigerating laboratories of the whole world put together, we were in a position to set up a practicum at the institute, which is attended by every student of the Moscow University School of Physics." At first, only the best students were admitted; but later every student was allowed to do two or three experiments, using liquid helium for the study of such phenomena as supraconductivity and magnetic properties near $0^{\circ} \mathrm{A}$. The best of the students, if they wished, were allowed to do more than the three experiments, and from the beginning of their third or fourth university year were in close contact with the Institute. Later they were invited to help with the research work as junior laboratory assistants. Prof. Kapitza thinks that if the scheme had not been interrupted by war, probably one out of ten or fifteen of these students, on completing their graduate work, would have proved sufficiently talented to remain on the main scientific staff of the Institute.

"This method of observing young students from the time they are at the university, the thorough and constant verification of their abilities is, in my opinion, the only correct way of selecting young scientific workers, so far. . . . As you grow older, it is only young people, only your pupils, who can save you from premature mental staleness. Of course, every pupil must know more about the field in which he is working than his teacher. And who teaches the teacher, but his pupils? Thanks to his experience the teacher supervises the general fund of the work, but he is taught by his pupils, who deepen his knowledge and extend his scope." The difficulty of making correct statements about the human being doing creative work is illustrated by Kapitza's statement that "without pupils the scientist very soon dies as a creative unit and ceases to advance". Faraday had no pupils. Rutherford told Kapitza that "it is only because of my pupils that I, too, feel so young". Prof. Kapitza ends the first section of his address with the words "as I myself am approaching old age, I feel that intercourse with youth must be the modus vivendi, safeguarding one from withering away and insuring the maintenance of courage and interest in all that is new and advanced in science. Conservatism in science is worse than premature death to a scientist; it acts as a brake on the development of science."

W. H. GEORGE.

\section{OBITUARIES}

\section{Dr. G. D. Bengough, F.R.S.}

Dr. Guy Dunstan Bengough, whose name is particularly associated with research on the corrosion of metals, died in the East Sussex Hospital, St. Leonards, on January 20. He was born in 1876, the son of Major E. B. Bengough, and was educated at Malvern and at Selwyn College, Cambridge. He then studied metallurgy at the Royal School of Mines and worked for a short time at the Royal Mint, gaining experience in research under Sir William RobertsAusten. He went to Burma for practical experience in the extraction of gold and tin ores, and then held teaching posts in the Universities of Birmingham and Liverpool.

While at Liverpool, Bengough published papers on the rupture of metals at high temperatures, in which he showed that the normal fracture through the crystals of a metal gave place to one passing between the crystal grains when a certain critical temperature was exceeded. This he attributed to the presence between the grains of a non-crystalline layer, having some of the properties of a glass, being rigid at low and viscous at high temperatures. The same idea was suggested independently by Dr. Rosenhain, and this conception of an 'amorphous intercrystalline cement', although questioned by some, became popular, and long served as a basis for research.

It was while at Liverpool that Bengough began work on the corrosion of metals, especially brass marine condenser tubes, for the Institute of Metals. A series of reports was issued, in which the conditions determining general corrosion and pitting were exam. ined, and new experimental methods were devised. The work was interrupted by the War of 1914-18. Bengough obtained a commission in the Royal Artillery, and in 1916 was captain and adjutant. $\mathrm{He}$ was, however, seconded for work for the Admiralty and later for the Royal Flying Corps, and continued work on corrosion in the Royal School of Mines. $\mathrm{H}_{\Theta}$ later became a principal scientific officer in the Chemical Research Laboratory at Teddington, and from then onwards devoted himself to the investigation of corrosion, giving special attention to the design of apparatus.

In 1926 Bengough devised the method of anodic protection of aluminium and its alloys which proved of very great industrial value. Not only did the film produced by his method give a high degree of resistance to corrosion, but also it could be given a definite degree of porosity, so that the surface could be made to take dyes or pigments, opening up a wide field of 